\title{
Corrigendum: Multi-Dimensional Plant Element Stoichiometry- Looking Beyond Carbon, Nitrogen, and Phosphorus
}

\author{
Göran I. Ågren ${ }^{1 *}$ and Martin Weih ${ }^{2}$ \\ ${ }^{1}$ Department of Ecology, Swedish University of Agricultural Sciences, Uppsala, Sweden, ${ }^{2}$ Department of Crop Production \\ Ecology, Swedish University of Agricultural Sciences, Uppsala, Sweden
}

Keywords: ecological stoichiometry, elementome, ionome, homeostasis, mineral nutrients, plant growth, scaling, stoichiometric niche volume

\section{A Corrigendum on}

Multi-Dimensional Plant Element Stoichiometry-Looking Beyond Carbon, Nitrogen, and Phosphorus

by Ågren GI and Weih M. (2020). Front. Plant Sci. 11:23. doi: 10.3389/fpls.2020.00023

Edited and reviewed by:

Sebastian Leuzinger,

Auckland University of Technology,

New Zealand

${ }^{*}$ Correspondence: Göran I. Ågren goran.agren@s/u.se

Specialty section: This article was submitted to Functional Plant Ecology, a section of the journal Frontiers in Plant Science

Received: 06 May 2020 Accepted: 04 June 2020

Published: 03 July 2020

Citation:

Ågren Gl and Weih M (2020) Corrigendum: Multi-Dimensional Plant

Element Stoichiometry-Looking

Beyond Carbon, Nitrogen, and Phosphorus.

Front. Plant Sci. 11:915.

doi: 10.3389/fpls.2020.00915
In the original article, the numerical values of the scaling exponents in the text, tables, and figures were incorrectly stated. This was due to a misinterpretation of the algorithm for calculating the scaling exponent. We provide here revised tables and figures (Figures 3, 4, 5, Tables 1, 4, 5) and changes in the text, where the value of the scaling exponent is important.

In Abstract the text should read

We show that the scaling exponent is rather insensitive to environmental conditions or species and ranges from -3.804 to 1.976 (average 0.384 ) in nine out of ten data sets. For single elements, $\mathrm{Mg}$ has the smallest scaling exponent (0.524) and Mn the largest (2.666). In two of the ten data sets the scaling exponent is negative but positive in the other eight sets.

In Materials and Methods, sub-section Theory

"...the range $c_{n, \max }-c_{n, \text { opt }}$ of the response niche..." should read

"...the range $c_{n, \text { min }}-c_{n, \text { opt }}$ of the response niche..."

In Results

"We note that taken over all data sets the scaling between $\mathrm{N}$ and $\mathrm{P}$ is $P \propto N^{1.04 \pm 0.02 \text { " }}$ should read

“...the scaling between $\mathrm{N}$ and $\mathrm{P}$ is $P \propto N^{0.21 \pm 0.05 \text { ” }}$ 


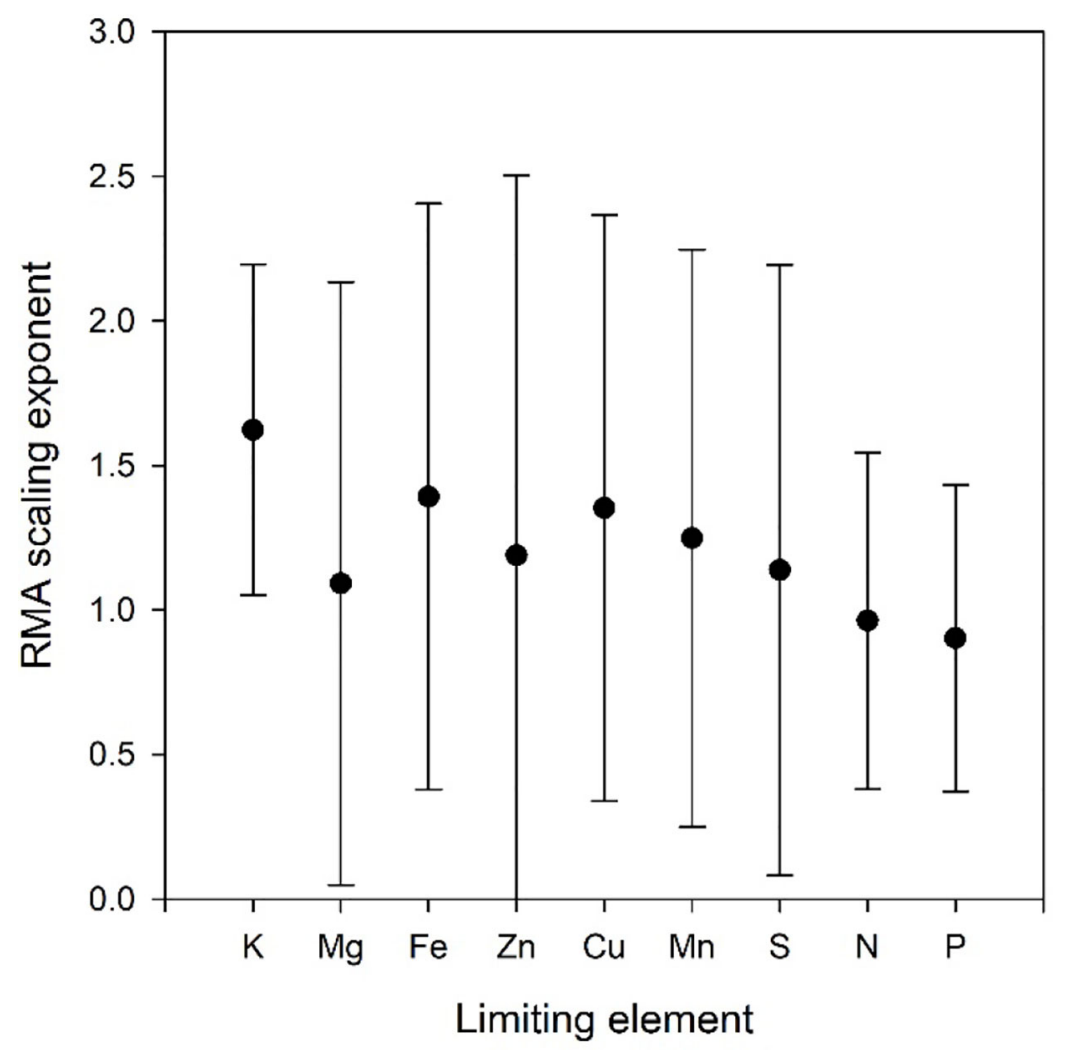

FIGURE 3 | Scaling exponents with 95\% confidence intervals as a function of limiting element in the Birch data set. All refers to the scaling exponent when data for all limiting elements are combined.

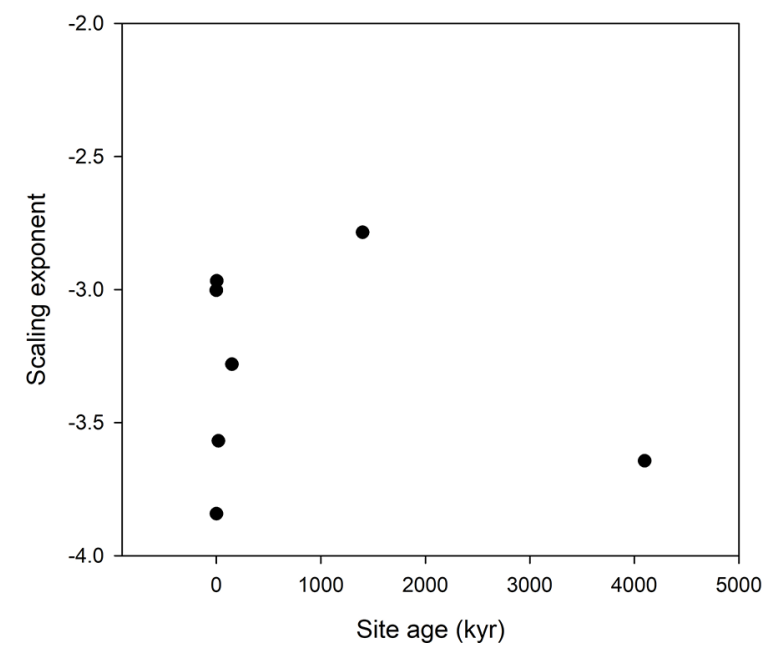

FIGURE 4 | Scaling exponents as function of site age in the Hawaii data set. The lowest age is the value for the scaling taken over all ages.

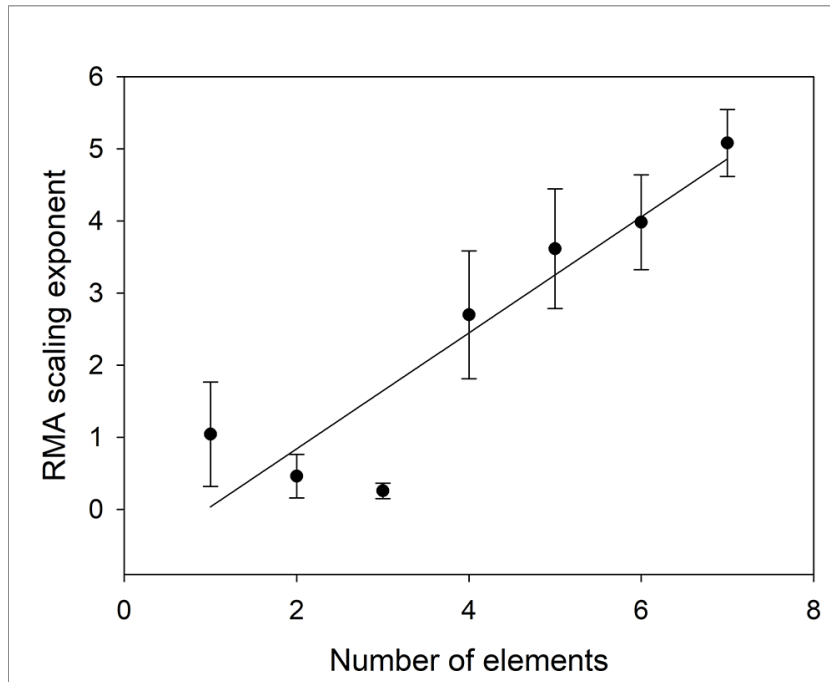

FIGURE 5 | Scaling exponent as a function of the number of elements included in VOth. The scaling exponent for $n=1$ is the average of the scaling exponents in Table 4. 
TABLE 1 | Summary of data sets used.

\begin{tabular}{|c|c|c|c|c|c|c|c|c|c|c|}
\hline & Tomato & Birch & Ideal & Wheat1 & Wheat2 & $\mathrm{CO}_{2}-\exp$ & Salix & $I C P$ & $I B P$ & Hawaii \\
\hline $\mathrm{P}, \mathrm{mg} / \mathrm{g}$ & * & * & * & * & * & * & * & * & * & * \\
\hline $\mathrm{K}, \mathrm{mg} / \mathrm{g}$ & * & * & * & * & * & * & * & * & * & * \\
\hline $\mathrm{Ca}, \mathrm{mg} / \mathrm{g}$ & * & * & & * & * & & * & * & * & * \\
\hline $\mathrm{Cu}, \mu \mathrm{g} / \mathrm{g}$ & & & * & * & * & $\left({ }^{*}\right)$ & & * & & \\
\hline$B, \mu g / g$ & & & & * & & $\left(^{*}\right)$ & * & & & \\
\hline $\mathrm{Zn}, \mu \mathrm{g} / \mathrm{g}$ & & & * & * & * & $\left({ }^{\star}\right)$ & * & * & & \\
\hline $\mathrm{Fe}, \mu \mathrm{g} / \mathrm{g}$ & & & * & * & * & * & * & * & & \\
\hline $\mathrm{Mn}, \mu \mathrm{g} / \mathrm{g}$ & & & * & * & * & * & * & * & & \\
\hline$\alpha$ & $\begin{array}{c}1.209 \pm \\
0.341\end{array}$ & $\begin{array}{c}1.363 \pm \\
0.587\end{array}$ & $\begin{array}{c}0.541 \pm \\
03772\end{array}$ & $\begin{array}{c}1,190 \pm \\
0.177\end{array}$ & $\begin{array}{c}0.746^{a} \pm \\
0.221\end{array}$ & $\begin{array}{c}0.207 \pm \\
0.070\end{array}$ & $\begin{array}{c}-1.262 \pm \\
0.200\end{array}$ & $\begin{array}{c}1.976 \pm \\
0.125\end{array}$ & $\begin{array}{c}1.676 \pm \\
0.351\end{array}$ & $\begin{array}{c}-3.804 \pm \\
0.258\end{array}$ \\
\hline
\end{tabular}

${ }^{a}$ Scaling computed for harvests $\mathrm{BBCH} 23$ (3 tillers detectable) plus BBCH37 (beginning of stem elongation).

Asterisks, i.e. " $"$ in a column indicate that the element is included in the data set, and. $\alpha_{\mathrm{RMA}}$ are the RMA scaling exponents between $\mathrm{V}_{\mathrm{NP}}$ and $\mathrm{V}_{\mathrm{Oth}}$ with $95 \%$ confidence intervals with only $\mathrm{K}$, $\mathrm{Ca}$, and $\mathrm{Mg}$ (K and $\mathrm{Mg}$ in Ideal) included in Oth. For data sets with more than one subset, the scaling is for the entire set. $r$ is the Ordinary Least-Squares regression coefficient. All $r^{2}$ except for $\mathrm{CO}_{2}$, Sallix and Hawaii, are significant at $1 \%$ level.

TABLE 4 | RMA scaling exponents $\left(\alpha_{R M A}\right)$ with 95\% confidence intervals for regressions between $\ln \left(V_{N P}\right)$ and $\ln (V O t h)$ for data sets that can be split into subsets. For Wheat2 All refers to $\mathrm{BBCH} 23$ plus $\mathrm{BBCH} 37$. All $\mathrm{r}^{2}$, except for $\mathrm{CO}_{2}$ and Salix, are significant at $1 \%$ level.

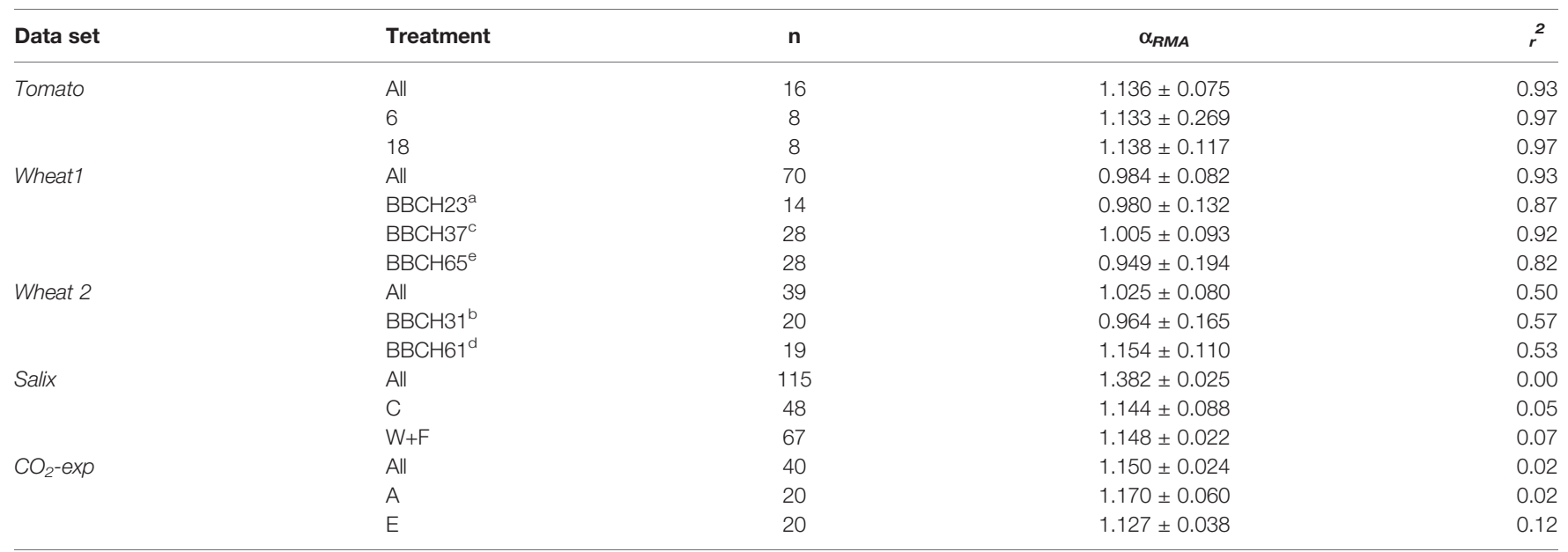

${ }^{a} \mathrm{BBCH} 233$ tillers detectable.

${ }^{b} \mathrm{BBCH} 31$ beginning of stem elongation.

${ }^{\circ} B B C H 37$ flag leaf visible.

${ }^{d} B B C H 61$ beginning of flowering.

${ }^{e} \mathrm{BBCH} 65$ full flowering.

TABLE 5 | RMA scaling exponents $\left(\alpha_{R M A}\right)$ with 95\% confidence intervals for regressions between $\ln \left(V_{N P}\right)$ and one single elements calculated from the combined Wheat 1, Wheat2, plus ICP data and the Ideal data sets respectively. Note that Ca is missing in the Ideal data set.

\begin{tabular}{lcccccccc}
\hline Element & $\mathbf{M g}$ & $\mathbf{S}$ & $\mathbf{C u}$ & $\mathbf{C a}$ & $\mathbf{K}$ & $\mathbf{Z n}$ & $\mathbf{F e}$ & $\mathbf{M n}$ \\
\hline Combined & $0.524 \pm$ & $0.477 \pm$ & $0.927 \pm$ & 1.030 & $0.698 \pm$ & $0.611 \pm$ & $1.400 \pm$ & $2.666 \pm$ \\
& 0.120 & 0115 & 0.118 & 0.110 & 0.101 & 0.127 & 0.094 \\
Ideal & $0.297 \pm$ & $0.449 \pm$ & $0.307 \pm$ & & $0.2487 \pm$ & $0.742 \pm$ & $0.582 \pm$ & $0.394 \pm$ \\
& 0.480 & 0306 & 0.473 & & 0.259 & 0.349 & 0.157
\end{tabular}


The last sentence of Results should be replaced by

Figure 5 shows that the scaling exponent increases linearly with number of elements $(n)(\alpha=-0.7687$ $\left.+0.8044 n, \mathrm{r}^{2}=0.8449\right)$.

In Discussion (last sentence of first paragraph) the text should be replaced by

We no longer observe a trend with site age in the Hawaii data set. We have no explanation for the negative scaling exponent in this data set. On the other hand, the negative scaling exponent in the Salix data set is a result of dilution of some micronutrients caused by increased growth by heavy NP fertilization.

The authors apologize for this error and state that this does not change the scientific conclusions of the article in any way. The original article has been updated.

Copyright (c) 2020 Agren and Weih. This is an open-access article distributed under the terms of the Creative Commons Attribution License (CC BY). The use, distribution or reproduction in other forums is permitted, provided the original author(s) and the copyright owner(s) are credited and that the original publication in this journal is cited, in accordance with accepted academic practice. No use, distribution or reproduction is permitted which does not comply with these terms. 